\title{
Association between the Facial Type and Morphology of the Upper Central Incisor in Normal Occlusion Subjects
}

\author{
${ }^{1}$ Luiz Renato Paranhos, ${ }^{2}$ Miller Zaroni, ${ }^{3}$ João Paulo de Carli, ${ }^{4}$ Roberta Okamoto, \\ ${ }^{5}$ Lucas Villaça Zogheib, ${ }^{6}$ Fernando César Torres
}

\begin{abstract}
Aim: The purpose of this study was to verify the association between the facial type and the morphology of the upper central incisor, to potentially provide a guide for artificial tooth selection in esthetic and prosthetic rehabilitation.

Materials and methods: The sample consisted of 51 lateral teleradiographs (lateral cephalometric radiographs) and cast models of subjects with a naturally optimal occlusion and at least four of the six keys of Andrews, for optimal occlusion. The facial type was defined by two cephalometric measurements (SN.Gn and SN.GoGn) and classified into dolichofacial, mesofacial and brachyfacial after digitizing the radiographs. The incisor morphology was classified into quadrangular, oval and triangular after 3D digitizing the models and evaluation of the images by 12 dentists. The evaluation between the examiners was performed by Kappa test. In order to test the differences between the variables, it was used a chi-square test (5\%).
\end{abstract}

Results: No significant difference $(p<0.05)$ was found between the studied variables.

Conclusion: Facial type was not associated with the morphology of the upper central incisor, considering the methodology and population included in the present study.

Clinical significance: Using the facial type as a way to select the morphology of the upper central incisor proved to be inadequate in this study.

Keywords: Tooth, Artificial, Cephalometry, Form perception, Incisor.

How to cite this article: Paranhos LR, Zaroni M, de Carli JP, Okamoto R, Zogheib LV, Torres FC. Association between the Facial Type and Morphology of the Upper Central Incisor

${ }^{1,3-5}$ Professor, ${ }^{2}$ Orthodontist, ${ }^{6}$ Associate Professor

${ }^{1}$ Department of Orthodontics, School of Dentistry, Federal University of Sergipe, Lagarto, SE, Brazil

4,5 Department of Oral Biology, Universidade Sagrado Coração São Paulo, Brazil

${ }^{2}$ Department of Orthodontics, Private Clinic, São Paulo, Brazil

${ }^{3}$ Department of Dentistry, Universidade de Passo Fundo, São Paulo, Brazil

${ }^{6}$ Department of Orthodontics, University of São Paulo, São Paulo, Brazil

Corresponding Author: Fernando César Torres, Associate Professor, Department of Orthodontics, University of São Paulo, City-UNICID, São Paulo, Brazil, e-mail: fernandozzy@hotmail.com in Normal Occlusion Subjects. J Contemp Dent Pract 2014; 15(1):29-33.

Source of support: Nil

Conflict of interest: None

\section{INTRODUCTION}

The concern about facial esthetics has followed the development of civilizations that have always used the face as the representative ideal of beauty as a reference. ${ }^{1}$ Smile is considered an important part of this standard of beauty. The smile harmony involves since its amplitude until the proportion with facial lines, color, and shape of the teeth as well as gingival exposure and contour. ${ }^{2}$

In relation to tooth shape, it is fundamental to know the anatomical characteristics of the dental crown, especially of the anterior teeth, aiming to conduct the different kinds of oral rehabilitation in equilibrium with the face. ${ }^{3}$ Given the lack of records previous to tooth loss, several parameters have been proposed to select the shape and size of the tooth. ${ }^{4}$ Among the theories intending to determine the shape of the upper central incisor, by means of facial measurements, the Berry Theory (1906) sought for the similarity between the morphology of the upper central incisor and the facial shape. ${ }^{4}$

In 1914, Williams ${ }^{5}$ classified the face morphology into triangular, quadrangular, and oval, and suggested that the upper central incisor should be selected according to the basic geometric shapes of the facial contour. Such association, although subjective, was adopted by several authors and still is a model used for presentation of artificial teeth by the manufacturers. ${ }^{3-6}$ Despite of this, Sellen et al ${ }^{7}$ stated that there is not a necessary relationship between the face and teeth morphology, and other aspects should be considered for the selection of tooth shape.

In order to characterize the face, the craniofacial growth may be described and quantified by presenting dimensional, angular and topographic individualities. The facial skeletal pattern, frequently referred as facial type, when is radiographically analyzed, may be classified into dolichofacial (longer and narrower face), brachyfacial (shorter and wider face) and a intermediary category, the mesofacial. ${ }^{8}$ The facial morphology is early defined and maintained during the growth, setting the genetic control on determining the skeletal framework. ${ }^{9,10}$ 
The lack of consensus in literature about a direct method using reliable anatomical parameters for selecting artificial teeth, led to this study, in order to test the hypothesis that facial skeletal pattern has a relationship with upper central incisor morphology.

\section{MATERIALS AND METHODS}

\section{Participants and Research Criteria}

This is an analytical observational study approved by the Research Ethics Committee of UMESP, São Bernardo do Campo, Brazil (protocol number 301919-09), developed with cast models and lateral teleradiographs of 95 individuals, selected from 13,618 preschool students, with natural normal occlusion (presence of at least four of the six Andrews ${ }^{11}$ keys for optimal occlusion). This sample derived from a file of 95 pairs of dental cast models and 95 lateral teleradiographs of Brazilian individuals, Caucasian, being 41 males and 54 females.

It was included in the study, the cast models of individuals above 15 years old, without craniofacial malformations, no important facial asymmetries, without odontogenic anomalies, with upper and lower incisors intact and healthy, and with all permanent teeth in occlusion, except for the third molars, and no history of previous orthodontic treatment. Models that presented a laboratory error and fractured teeth, hindering the localization of the landmarks, as well as opaque teleradiographs that hampered the cephalometric tracing, were excluded from the sample.

\section{Methods}

In order to define the vertical facial skeletal pattern (facial type), the following cephalometric landmarks were used: $\mathrm{N}$ (nasion), S (sella), Go (gonion), Gn (gnathion). From the landmarks, we achieved the following angular measurements: SN.GoGn - angle between the planes SN and GoGn. Standard ${ }^{12}$ preset: $32^{\circ}$, with variation of plus or minus $5^{\circ}$; and SN. Gn - angle formed between the lines SN and SGn. Standard ${ }^{13}$ preset: $67^{\circ}$, with variation of plus or minus $3^{\circ}$ (Figs 1A to C).

After obtaining the angular measurements (SN.Gn and SN.GoGn), the sample was classified into dolichofacial (SN. Gn equal to or higher than $70.1^{\circ}$ ), mesofacial (SN.Gn from $64.1^{\circ}-70^{\circ}$ ) and brachyfacial (SN.Gn equal to or lower than $64^{\circ}$ ), according to Steiner, ${ }^{13}$ and into dolichofacial (SN. GoGn equal to or higher than $37.1^{\circ}$ ), mesofacial (SN.GoGn from $27^{\circ}$ until $37^{\circ}$ ) and brachyfacial (SN.GoGn equal to or lower than $26.9^{\circ}$ ), according to Riedel. ${ }^{12}$ After classifying the facial type, the sample was modified again aiming to set apart the coincident facial types, that is, when both SN.Gn and SN. GoGn indicated the same pattern. The individuals that did not achieve the coincidence of measurements were excluded from the sample, thus resulting in 51 individuals. This final sample presented the mean age of 16 years and 6 months, ranging from 15 years and 2 months to 19 years and 4 months, being 21 (41.2\%) males, and $30(58.8 \%)$ females.

The 51 cast models were digitized (Dental Wings Scanner, dw5-140, Dental Wings, Inc, Montreal, Canada) and the obtained images were treated with a vectorial software (Corel Draw X3, Corel, Ottawa, Canada) for later analysis. Onto the image of each model, the upper right central incisor was enlarged to the size of $10 \mathrm{~cm}$, for standardization and better analysis accuracy. To improve the visualization, a negative image was created, with dark background (Figs 2A to D).

Each image was arranged in the center of a white paper sheet $(8.27 \times 11.69$ inches $)$ with $90 \mathrm{~g} / \mathrm{m}^{2}$, under pre-established models of dental crown that comprised an album. On each page, it was presented the dental models classified into quadrangular, oval and triangular. After that, we distributed individually to 12 previously trained dentists, one album containing all crown images. It was requested them to tick the shape most matching the presented crowns. After 1 week, the material was gathered by the responsible researcher.

\section{Statistical Analysis}

For data analysis, we evaluated the error of the method, by performing a second cephalometric landmark on the image of 20 teleradiographs randomly selected. The approximate interval between the first and the second assessment was 2 weeks.

In order to test the systematic error, it was used the paired t-test, adopting the significance level of $5 \%$. In determining the casual error, it was used the Dahlberg formula. To verify the concordance between the evaluators when classifying the morphology of the upper central incisor, the Kappa test was applied, and interpreted according to Landis and Koch $(\mathrm{p}<0.05)$. A possible association between the facial type (dolichofacial, mesofacial and brachyfacial), and the morphology of the central incisor (quadrangular, oval and triangular) was checked by the chi-square test. For all statistical tests, the significance level was set at $5 \%$.

\section{RESULTS}

According to Landis and Koch, the concordance value between the evaluators was moderate (0.52). Considering the evaluators conclusion, the dental crown shapes were determined by concordant results obtained by the majority. The chi-square test evidenced no significant difference between the facial type and the teeth shape (Table 1).

\section{DISCUSSION}

The ideal shape of teeth is important not only for the functional and biological rehabilitation, but also a parameter 

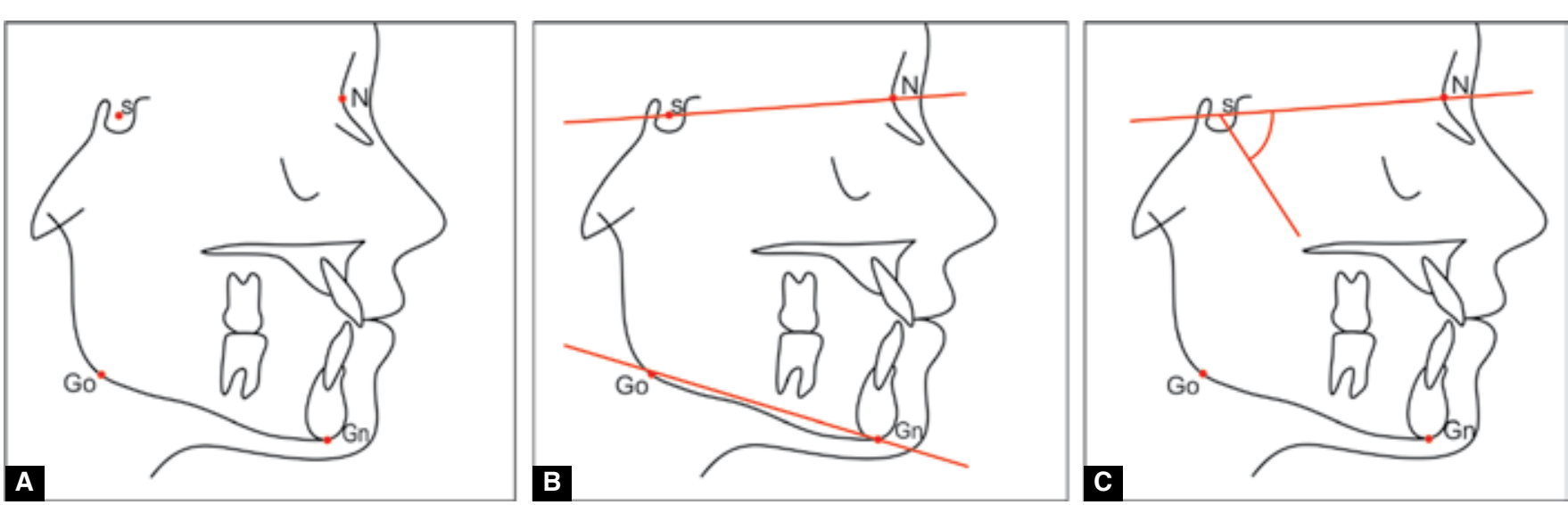

Figs 1 A to C: (A) Cephalometric landmarks, (B) angle measurements used (SN.GoGn) and (C) SN.Gn
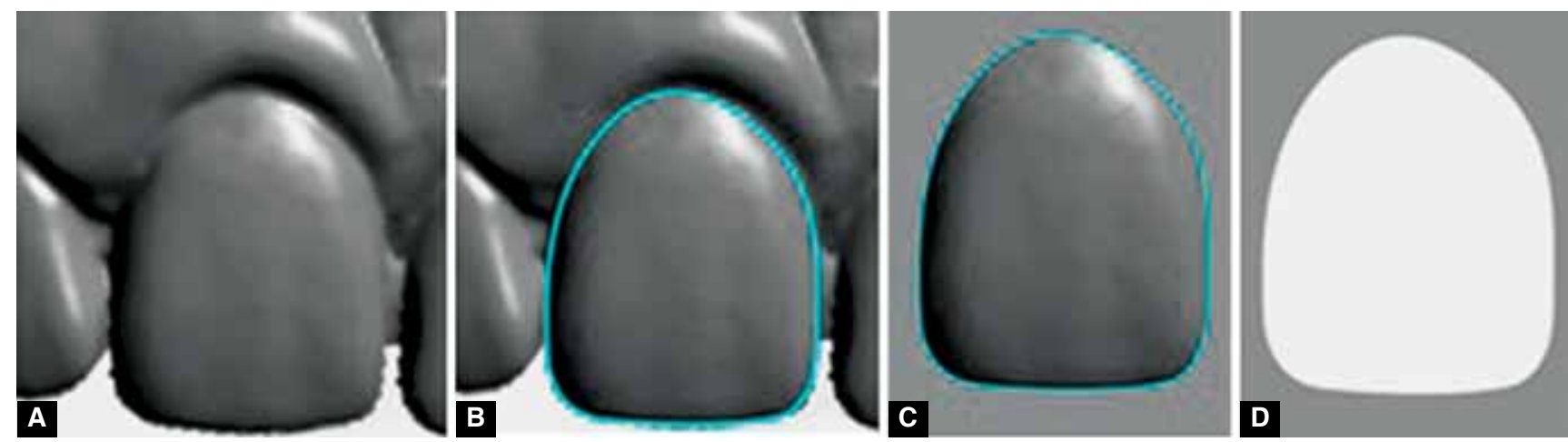

Figs 2A to D: (A) Image of the upper right central incisor imported into Corel Draw X3), (B) delimitation of dental shape, (C) isolated image of the incisor crown and (D) negative image of the crown

to be sought aiming a pleasing esthetics, in harmony with the face of the patient prosthetically rehabilitated. Considering this, it is necessary to search objectively the possible relationships among the several variables in the orofacial complex, with the purpose to find strong associations that may increase the final predictability of the dental treatment.

Selecting the artificial teeth shape is considered a challenge for the professionals that seek using scientific resources in the prosthetic rehabilitation of edentulous patients with no previous records of the teeth shape. Subjective criteria, such as temperament ${ }^{4}$ and face shape, ${ }^{3,5-7}$ added to the patient ethnicity ${ }^{4}$ and sex, although widely used, are not always enough to fulfill the esthetic expectation of the patients.

Several studies have been proposed to find more objective criteria that could ease the selection of artificial teeth. Hasanreisoglu et $\mathrm{al}^{14}$ (2005) observed that the dimensions of the bizygomatic and interalar widths may assist in the selection of ideal width of upper front teeth, particularly in women. Petricević et $\mathrm{l}^{15}$ (2005) verified that the width and height of the upper central incisor may be calculated from the bone palate measurements, and that the width of the hamular notch corresponds to the width of six upper front teeth. Al-Khatib et al ${ }^{16}$ (2007) found a significant correlation between the teeth size with the dental arch dimensions. Nevertheless, no study proposed to exactly verify the teeth shape, but only the teeth dimension and the relationship with other dimensions of the orofacial complex.

The purpose of this study was to verify any relationship between the facial type (determined by cephalometry) and the morphology of the upper central incisive.

The computerized cephalometric analysis allowed a careful analysis of the obtained angles through landmarks

Table 1: Facial type and teeth morphology. Note that although nonsignificant there is a higher incidence of oval teeth in mesofacial individuals

\begin{tabular}{llcccc}
\hline Facial type & & \multicolumn{3}{c}{ Tooth shape } & Total \\
\cline { 3 - 5 } & & Oval & Quadrangular & Triangular & \\
\hline Brachy & $\mathrm{n}(\%)$ & $11(45.8)$ & $8(33.3)$ & $5(20.8)$ & $24(100.0)$ \\
Meso & $\mathrm{n}(\%)$ & $7(50.0)$ & $4(28.6)$ & $3(21.4)$ & $14(100.0)$ \\
Dolicho & $\mathrm{n}(\%)$ & $6(46.2)$ & $4(30.8)$ & $3(23.1)$ & $13(100.0)$ \\
\hline Total & $\mathrm{n}(\%)$ & $24(47.1)$ & $16(31.4)$ & $11(21.6)$ & $51(100.0)$ \\
\hline
\end{tabular}

$\chi^{2}=0.12 ; p=0.998$ (nonsignificant) 
located in the lateral teleradiograph, providing an accurate information as for the desired angle. These angles may lead to distinct diagnoses in the determination of the facial type. ${ }^{17-19}$ In order to minimize the chance of diagnosis error, it was used in this study, the Riedel ${ }^{12}$ and Steiner ${ }^{13}$ analyses to determine the facial skeletal pattern. In this study, the SN.GoGn and SN.Gn angles were used, once the SN.GoGn angle reveals the relationship between the mandibular base and cranial base, and the SN.Gn angle defines the resultant vectorial of the anterior and inferior growth of the mandibular, also known as Y growth axis. These two measurements interpreted together allow the perception of the actual direction of the facial growth vector, ${ }^{20}$ besides using easily located landmarks, reducing the margin of error.

The 3D digitizing device used in the models in this study produced precise images of dental anatomy that could be easily distorted by photographic records. These images were subjected to several comparisons between different expert professionals, which classified them into three basic shapes (quadrangular, triangular and oval), as suggested by several authors. ${ }^{4-6,21}$

In relation to the sex, studies have affirmed that men have dental $\operatorname{arch}^{16,22}$ and teeth larger than women. ${ }^{16}$ Souza et $\mathrm{al}^{6}$ (1997), evaluating a population of women between 20 and 25 years old, have observed the triangular shape of the upper central incisor as the most common (45.9\%), followed by quadrangular (40.5) and oval (13.6). Brunetto et $\mathrm{al}^{23}$ (2011) registered that the oval shape was the most prevalent in both sexes. However, the triangular shape was most common in men and the quadrangular in women. Paranhos et $\mathrm{al}^{21}$ (2010) found the majority being oval (47.06\%), followed by quadrangular (31.37\%) and triangular (21.57), disregarding the sex.

Studies with twins showed that the tooth crown size is determined by the genetics, ${ }^{24}$ once the size of the teeth, as well as of the jaws, are linked to the genome, and may lead to the appearance of dental crowding and spacing. Therefore, the tooth size appears to have a positive association with the arch shapes. ${ }^{25}$ This could be used as a criteria to determine tooth morphology, in rehabilitation cases.

In the present study, although the results had no significant difference, there was a greater incidence of the oval shape in mesofacial type subjects. Corroborating this, Halazonetis ${ }^{26}$ in 2007 , observed that the facial type was correlated to the position of the incisors lower edge, being shorter, longer or oval. Therefore, it was observed that the tooth size may be determined by a combination of genes coming from the parents, as well as the maxillary size.

The relationship between the size of the central incisor and the facial type was previously studied, but it was only confirmed that dolichofacial individuals presented longer teeth than mesofacial individuals, due to the roots size. ${ }^{27}$
Berksun et al ${ }^{28}$ using standardized digital photographs, sought to verify a subjective correlation between the facial morphology and the dental arch and the tooth shape, however, they found a not high correlation.

The data of the present study evidenced no significant statistical association between the facial type and the tooth morphology. The methodology employed must be considered: individuals with optimal occlusion the ethnic composition of the sample, and the measurements used.

\section{CONCLUSION}

Using the facial type (SN.GoGn and SN.Gn) as a way to select the morphology of the upper central incisor proved to be inadequate, considering the methodology and population included in the present study.

\section{REFERENCES}

1. Basciftci FA, Uysal T, Buyukerkmen A, Demir A. The influence of extraction treatment on Holdaway soft-tissue measurements. Angle Orthod 2004 Apr;74(2):167-173.

2. McLaren EA, Rifkin R. Macroesthetics: facial and dentofacial analysis. J Calif Dent Assoc 2002 Nov;30(11):839-846.

3. Pedrosa VO, França FM, Flório FM, Basting RT. Study of the morphodimensional relationship between the maxillary central incisors and the face. Braz Oral Res 2011 MayJun;25(3):210-216.

4. Sellen PN, Jagger DC, Harrison A. Methods used to select artificial anterior teeth for the edentulous patient: a historical overview. Int J Prosthodont 1999 Jan-Feb;12(1):51-58.

5. Williams JL. A new classification of human tooth forms, with special reference to a new system of artificial teeth. Dental Cosmos 1914 Feb;56(5):627-628.

6. Souza JCF, Tamaki T, Tamaki TS. Estudo comparativo da forma do contorno vestibular do incisivo central superior com a forma do rosto. RPG Rev Pós-Grad 1997 Apr-Jun;4(2):114-120.

7. Sellen PN, Jagger DC, Harrison A. Computer — generated study of the correlation between tooth, face, arch forms and palatal contourn. J Prosthet Dent 1998 Aug;80(2):163-168.

8. Ricketts RM. The wisdom of the bioprogressive philosophy. Semin Orthod 1998 Dec;4(4):201-209.

9. Bishara SE, Jakobsen JE. Longitudinal changes in three normal facial types. Am J Orthod 1985 Dec;88(6):466-502.

10. Fishman LS. Individualized evaluation of facial form. Am J Orthod Dentofacial Orthop 1997 May;111(5):510-517.

11. Andrews LF. The six keys to normal occlusion. Am J Orthod 1972 Sep;62(3):296-309.

12. Riedel RA. The relation of maxillary structures to cranium in malocclusion and in normal oclusion. Angle Orthod 1952 July;22(3):142-145.

13. Steiner CC. Cephalometrics in clinical practice. Angle Orthod 1959 Jan;29(1):8-29.

14. Hasanreisoglu U, Berksun S, Aras K, Arslan I. An analysis of maxillary anterior teeth: facial and dental proportions. J Prosthet Dent 2005 Dec;94(6):530-538.

15. Petricević N, Katunarić M, Mehulić K, Simeon P, Rener-Sitar $\mathrm{K}$, Celebić A. Selection of appropriate artificial frontal teeth size using dimensions of hard palate. Coll Antropol 2006 Sep; 30(3):573-577. 
16. Al-Khatib AR, Rajion ZA, Masudi SM, Hassan R, Anderson PJ, Townsend GC. Tooth size and dental arch dimensions: a stereophotogrammetric study in Southeast Asian Malays. Orthod Craniofac Res 2011 Nov;14(4):243-253.

17. Sassouni V. A roentgenographic cephalometric analysis of cephalo-facio-dental relationships. Am J Orthod 1955 Oct;41(10): 735-764.

18. Creekmore TD. Inhibition or stimulation of the vertical growth of the facial complex, its significance to treatment. Angle Orthod 1967 Oct;37(4):285-297.

19. Siriwat PP, Jarabak JR. Malocclusion and facial morphology is there a relationship? An epidemiologic study. Angle Orthod 1985 Apr;55(2):127-138.

20. Bishara SE, Augsburger EF. The role of the mandibular plane inclination in orthodontic diagnosis. Angle Orthod 1975 Oct; 45(4):273-281.

21. Paranhos LR, Jóias RP, Velasco L, Bérzin F, Daruge-Júnior E. Prevalence of the different maxillary central incisor shapes in individuals with natural normal occlusion. Braz J Oral Sci 2010 Apr-Jun;9(2):104-107.

22. Alvaran N, Roldan SI, Buschang PH. Maxillary and mandibular arch widths of Colombians. Am J Orthod Dentofacial Orthop 2009 May;135(5):649-656.
23. Brunetto J, Becker MM, Volpato CA. Gender differences in the form of maxillary central incisors analyzed using AutoCAD software. J Prosthet Dent 2011 Aug;106(2):95-101.

24. Mossey PA. The heritability of malocclusion: part 2. The influence of genetics in malocclusion. Br J Orthod 1999 Sep; 26(3):195-203.

25. Lee SJ, Lee S, Lim J, Parque HJ, Wheeler TT. Method to classify dental arch forms. Am J Orthod Dentofacial Orthop 2011 July; 140(1):87-96.

26. Halazonetis DJ. Morphometric correlation between facial soft-tissue profile shape and skeletal pattern in children and adolescents. Am J Orthod Dentofacial Orthop 2007 Oct; 132(4):450-457.

27. Simões W, Villi ER, Silva M. Correlação entre o comprimento total dos dentes incisivos centrais superiores permanentes com suas coroas e comaaltura-largura da face, nos tipos faciais de leucodermas brasileiros. Rev Odontol Univ São Paulo 1988 July-Sept; 2(3):148-152.

28. Berksun S, Hasanreisoglu U, Gökdeniz B. Computer-based evaluation of gender identification and morphologic classification of tooth face and arch forms. J Prosthet Dent 2002 Dec;88(6): 578-584. 